\title{
Configurações
}

Revista de sociologia

\section{Epistemologias feministas e mobilidade científica: contribuições para o debate}

Feminist epistemologies and scientific mobility: contributions to the debate

Épistémologies féministes et mobilité scientifique: contribution au débat

\section{Thais França e Beatriz Padilla}

\section{OpenEdition}

\section{Journals}

Edição electrónica

URL: http://journals.openedition.org/configuracoes/2203

DOI: $10.4000 /$ configuracoes.2203

ISSN: 2182-7419

\section{Editora}

Centro de Investigação em Ciências Sociais

Edição impressa

Data de publição: 1 Dezembro 2013

Paginação: 47-60

ISBN: 1646-5075

ISSN: 1646-5075

\section{Refêrencia eletrónica}

Thais França e Beatriz Padilla, « Epistemologias feministas e mobilidade científica:contribuições para o debate », Configurações [Online], 12 | 2013, posto online no dia 08 outubro 2014, consultado o 20 abril 2019. URL : http://journals.openedition.org/configuracoes/2203 ; DOI : 10.4000/ configuracoes. 2203

Este documento foi criado de forma automática no dia 20 Abril 2019. 


\title{
Epistemologias feministas e mobilidade científica:contribuições para o debate
}

\author{
Feminist epistemologies and scientific mobility: contributions to the debate \\ Épistémologies féministes et mobilité scientifique: contribution au débat
}

Thais França e Beatriz Padilla

\section{Epistemologias feministas: ultrapassar as fronteiras proibidas}

1 Os estudos feministas têm cada vez mais se legitimado como um campo de conhecimento sólido e inovador, tanto desde uma perspectiva teórico-metodológica como crítica. Têm empreendido um esforço hercúleo para dar visibilidade às problemáticas femininas dentro das ciências e lutado pelo reconhecimento das mulheres como sujeitos da história. Ao mesmo tempo, reclamam o caráter político da produção de conhecimento e denunciam o androcentrismo, o colonialismo, o universalismo e o eurocentrismo sobre o qual a ciência moderna está assentada. Além disso, como esclarece Bandeira (2008: 11), as críticas feministas, ao contraporem-se a categorias, conceitos e métodos hegemónicos, desafiam a si próprias a não reproduzirem a mesma dominação científica que julgam inadequadas. Exige-se, pois, das cientistas feministas uma vigilância teórica, epistemológica e metodológica perene e uma postura ética que constantemente (re)avalie sua prática e discurso para evitar a utilização de categorias coloniais, patriarcais, racistas e heteronormativas historicamente naturalizadas. Isto porque a utilização destas categorias produz mais negações, invisibilidades e silêncios do que propriamente contribui para a construção de um conhecimento emancipador (Simpson, 2012).

2 As cientistas feministas têm apontado como o modo tradicional de fazer e compreender a ciência resulta em um conhecimento excludente, unilateral e perverso, pois, via de regra, 'outras vozes' - femininas, negras, indígenas, não ocidentais, homossexuais, transexuais, 
rurais e imigrantes - são silenciadas (Harding, 1987). Ainda, este conhecimento, por se pretender 'universal' e 'objetivo', nega veementemente a 'experiência' como uma categoria válida de análise. Desta forma, as cientistas denunciam o caráter androcêntrico, sexista, classista e colonial da ciência moderna, que desde sua concepção até os dias atuais continua a invisibilizar qualquer sujeito que não seja o homem, branco, cristão, burguês e do Norte global como agente de produção de conhecimento (Grosfoguel, 2008; Neves e Nogueira, 2005).

3 Neste sentido, as epistemologias feministas tecem uma crítica severa à racionalidade e à neutralidade científica moderna quando expõem que os/as cientistas são atravessados/as por marcadores de classe, género, orientação sexual e raça/etnia e que sua biografia pessoal está, invariavelmente, presente em sua produção científica - em especial nas ciências sociais e humanas, que envolvem, quase sempre, a sustentação de um ponto de vista e posicionamento (Bandeira, 2008; Cunha, 2011). Ou seja, as críticas à ciência moderna não passam apenas pela maneira como ela vem sendo produzida, mas debatemse também sobre a forma como o/a cientista se implica e reconhece o lugar que ocupa neste labor e as consequências que as escolhas políticas trarão para o conhecimento produzido. Neste sentido, as críticas feministas avançam também, ao defender a importância do "conhecimento e experiência situada" (Haraway, 1988) que permite explicitar desde onde se faz e cria conhecimento.

4 São de registar, igualmente, as observações que os estudos feministas fazem à prática científica como sendo uma construção social e histórica específica e que, portanto, reproduz os valores dominantes e hegemónicos de cada época. Nas palavras de Narvaz e Koller (2006: 648), "[a]s teorias, antes que verdades absolutas, são apenas diferentes maneiras de construir e organizar o conhecimento e referendar uma práxis legitimada por determinada comunidade científica em determinado contexto histórico". Diante de tal entendimento, não é de se espantar que numa sociedade patriarcal como a nossa as práticas de produção científica tenham arraigadas dentro de si este ranço.

5 Consequentemente, diante de tal tradição conservadora e sexista, reproduz-se nas ciências o lugar subalterno e inferiorizado que tem sido reservado às mulheres na sociedade. Além disso, em termos de reconhecimento das mulheres como sujeitos produtores de saber, historicamente esse lugar lhes foi recusado através da naturalização do feminino (associação à natureza), de uma negação da objetividade e racionalidade assentadas em uma suposta fisiologia e psicologia feminina. Os estudos feministas vêm exigir, desta forma, o reconhecimento não apenas da mulher como sujeito da história, mas também como sujeito produtor de ciência, especialmente desde uma perspectiva crítica e autônoma.

\section{Metodologia}

Por tratar-se de um artigo declaradamente feminista, a metodologia que o atravessa também adota esse caráter. As epistemologias feministas, ao denunciarem a urgência de uma nova ciência, exigiram, instantaneamente, novas interpretações dos métodos de investigação e de produção de conhecimento, pois, como nos adverte Lord (1984: 110), "the master's tools will never dismantle the master's house".

7 Ademais, trata-se de um texto escrito a quatro mãos, porém, em primeira pessoa, porque renegamos os pressupostos da imparcialidade e neutralidade do conhecimento e 
assumimos nosso compromisso com a mudança social. Tal como nos ensina Harding (1986), concebemos o conhecimento como sendo sempre situado e advogamos a necessidade de resgatar o papel da emoção e da experiência dos/as investigadores/as neste processo. Procuramos, desta forma, oferecer novas interpretações de discursos enraizados sobre o fazer-ciência português, pois concebemos esta prática como uma forma de luta feminista e política contemporânea urgente (Schmidt, 2004). Neste sentido, almejamos contribuir para a desconstrução da crença de que mecanismos racistas ou sexistas de discriminação são inexistentes no meio académico científico em Portugal.

Além disso, posicionamo-nos como membros do grupo de subjugados/as (Haraway, 1988: 32), ou seja, o grupo cujo conhecimento produzido não é aceite de antemão, ou porque não há interesse, ou porque não se admite como um tema de investigação relevante, ou porque não se reconhece como legítimo.

9 Ao implicarmos a nossa própria biografia na tessitura deste artigo e assumirmo-nos como imigrantes latino-americanas (brasileira e argentina), académicas feministas radicadas em Portugal, deixamos claro, desde o início, o lugar de onde falamos - das fronteiras. E aqui, declararmo-nos como 'fronteiriças' implica que produzimos nossos conhecimentos a partir das margens e que identificamos este espaço como sendo fértil de produção de retórica, práxis e teoria feminista situada (Anzaldua, 2012).

Reconhecemos ainda a complexidade do nosso lugar de enunciação, pois, embora nos assumamos como 'vozes marginais', porque somos mulheres, feministas, imigradas do Sul global, dentro de uma academia patriarcal e conservadora, é igualmente verdade que ocupamos uma posição privilegiada como académicas num centro de investigação europeu. Daí a necessidade imperiosa de estarmos constantemente a examinar as nossas práticas de produção de conhecimento e as nossas opções epistemológicas e metodológicas.

11 Para este exercício, utilizamos a autorreflexividade, não apenas como um conhecimento em si mesmo, mas como uma possibilidade de indagar a realidade com base em pressupostos teóricos e no nosso próprio lugar de enunciação. "A dificuldade é a exigência de um constante escrutínio pessoal, ou seja, uma elevada capacidade crítica e analítica para que a reflexividade não se transforme em apenas mais uma descrição da mesma coisa" (Cunha, 2011: 79). Cientes desta adversidade e da complexidade em apresentar o refletido de forma inteligível e útil, contrastamos diversas vezes as nossas experiências entre nós mesmas, argumentamos profundamente o peso das nossas emoções, biografia, valores, ideologias, pressupostos políticos e éticos e por fi $\mathrm{m}$ contrapomos nossas experiências com as de outras não portuguesas académicas e cientistas residentes no país e que temos entrevistado, intercambiando percepções ao longo dos últimos anos.

Para o trabalho de crítica e reflexão que nos propomos, partindo do nosso próprio lugar de enunciação, a categoria 'experiência' é-nos muito cara. Como dito anteriormente, há da nossa parte uma rejeição da ideia de objetividade pura; optamos, por isso, por uma compreensão do conhecimento como sendo situado e parcial (Haraway, 1988). Isto é, procuramos basear a nossa produção partindo de um posicionamento crítico, localizado e conectado com a nossa situação, a nossa condição de classe, de raça, de nacionalidade, o nosso processo de formação académico e nossos trânsitos migratórios (Furlin, 2012). É por acreditarmos que a nossa experiência de mulheres, imigrantes latino-americanas, cientistas feministas pode ser alimento para teorizações futuras que decidimos não negligenciá-la nem invisibilizá-la. 
13 É fundamental perceber que a escolha de reconhecer na experiência um elemento sólido para nossas análises, bem como a opção de autorreflexividade enquanto método de investigação, não significa que em momento algum abrimos mão do rigor científico. Pelo contrário, o exercício empreendido para traduzir nossas enunciações e reflexões em conhecimento cognoscível e crítico exige um rigor ainda mais minucioso, todavia, um rigor sem obsessão por uma suposta neutralidade (Cunha, 2011).

\section{Cientistas imigrantes: confrontando as epistemologias dominantes}

14 Se a proposta é a construção de um outro modelo de ciência engajado e comprometido com a transformação social, é preciso abrir mão de toda ingenuidade e olhar criticamente para as próprias epistemologias feministas, pois há também feminismos hegemónicos que repetem padrões de dominação que excluem, segregam e oprimem outros grupos de mulheres - imigrantes, portadoras de deficiências, membros de minorias étnico-raciais ou de diferente orientação sexual. Hooks (2000), em suas análises sobre o feminismo ocidental hegemónico, denuncia a incapacidade (ou desinteresse) deste feminismo em incorporar as questões raciais e sua prática cotidiana de estereotipar as 'mulheres do Terceiro Mundo' como um todo homogéneo, em geral, pobres, ignorantes, vitimizadas e vulneráveis. Segundo ela, as mulheres que não correspondem às experiências vividas pelas mulheres brancas, heterossexuais ocidentais e de classe média são consideradas 'outras mulheres não emancipadas'.

15 Atualizando estas colocações para nossas discussões sobre a produção da ciência, as epistemologias feministas mais conservadoras reclamam também um modelo de mulher cientista dominante que representa a forma 'apropriada' de fazer ciência, que segue os cânones ofi ciais e que replica 'adequadamente' os métodos e as metodologias vigentes. As críticas de Mohanty (1986) mostram como algumas escolas de estudos feministas utilizam-se de metodologias, conceitos e categorias falaciosamente universais para servir aos interesses do feminismo ocidental.

16 Em outras palavras, a própria produção de conhecimento a partir de uma perspetiva feminista pode reproduzir padrões de colonização, opressão e dominação que em nada contribuem para a construção de uma ciência emancipadora e engajada com a transformação social. Desta forma, é fundamental reforçar a relevância da reflexão crítica sobre os conceitos, métodos e categorias utilizados, a fim de evitar a reprodução de padrões de dominação invisíveis.

17 Os efeitos das assimetrias geopolíticas também são sentidos nas ciências. As relações díspares de espaço, poder e saber resultam em certos territórios serem privilegiados como centros produtores de conhecimento (Norte) e outros relegados a uma posição de objeto de análise e de recetores passivos de conhecimento (Sul) (Almeida, 2011).

Pode-se dizer, portanto, que há no mundo uma hierarquia geográfica, epistémica e de género no que concerne a produção do conhecimento. Este é um ponto fundamental para analisar e compreender a experiência das investigadoras latino-americanas no meio científico português. Do mesmo modo, cabe considerar que dentro do Norte global e do Portugal global, também existem hierarquias geopolíticas, nestes casos determinadas pela centralidade/marginalidade das regiões (leia-se universidades, laboratórios, centros e 
institutos) produtoras de conhecimento e canalizadoras de recursos. Tal assimetria resulta naquilo que se pode chamar "ditadura da produção e localização científica".

Estas críticas tornam-se ainda mais pertinentes neste momento em que a mobilidade científica se tem intensificado entre diferentes instituições do mundo. A tendência atual para a internacionalização da ciência faz com que cada vez mais experiências em projetos com distintos países e a participação em redes internacionais sejam vitais para o desenvolvimento da carreira científica (Ackers, 2005; Bauder, 2012).

Desta forma, a circulação constante de cientistas entre laboratórios, universidades, centros e institutos possibilita que se contraponham diferentes formas de fazer ciência, bem como sujeitos produtores de ciência com outras origens, backgrounds, conceções e opções metodológicas igualmente distintas.

21 A relevância que este tipo específico de mobilidade geográfica implica pode ser percebida a partir da construção social e política que o sustenta. Por um lado, é possível justificar a opção pelo uso da terminologia "mobilidade científica", em virtude da temporalidade e da multiplicidade de espaços que, usualmente, esses deslocamentos envolvem (Ackers, 2010; King, 2002). Por outro, não se pode dissociar do fato de que se trata também de uma escolha ideológica que demarca, desde o início, uma distinção de classes sociais (Reis et al., 2010).

Enquanto aos/às demais trabalhadores/as de outras nacionalidades que se inserem no mercado laboral precário recai o fardo e o estereótipo da palavra 'imigrante', os/as cientistas protagonizam uma 'mobilidade científica' e aqueles/as que possuem altas qualificações são chamados/as de 'talentos'. No entanto, nem sempre é clara a distinção entre ser imigrante cientista qualificado/a ou talento em mobilidade, nem a diferença na produção do conhecimento científico desde uma ou outra categoria.

Contudo, apesar dos esforços políticos em dar uma roupagem distinta a esses fluxos migratórios, a 'mobilidade científica' continua a ser um fenómeno social. Logo, não é possível esquecer que diversos marcadores de diferença estarão presentes e moldarão parte significativa desta experiência de acordo com suas interações. Raça, género, etnia, nacionalidade, sexualidade, religião são eixos que não podem ser descurados nas análises das dinâmicas que envolvem a mobilidade científica, por mais 'sofisticada' que ela seja. Reconhecer este caráter situado e historicizado do/a cientista é uma das principais demandas das epistemologias feministas. Isto porque a forma como esses eixos se cruzarão resultará em experiências qualitativamente diferentes (Brah, 2006) que se refletirão de forma particular no conceber e produzir conhecimento de cada cientista.

No caso específico das mulheres cientistas, a invisibilidade que este tema possui nas investigações internacionais, a ausência de preparação que, em geral, os centros possuem para receber 'cientistas mães', a inexistência de políticas internas das instituições para a promoção da igualdade de gênero atestam como a experiência de uma mulher cientista pode ser significativamente prejudicada quando comparada àquela de um homem cientista. 0 simples fato de trabalhar num ambiente tão especializado e qualificado como o científico não torna as mulheres imunes a uma série de opressões, estereótipos, obrigações e dominações existentes na sociedade (Prado e Fleith, 2012). Nas palavras de Velho e Léon (1998: 309), "padrões de produção científica são socialmente construídos e nesse caso eles evidenciam as construções sociais de gênero na academia".

Outro aspecto também pouco abordado dentro das reflexões sobre mobilidade científica diz respeito ao próprio processo de legitimação e produção de saberes. Se uma das 
maiores vantagens que o deslocamento internacional de cientistas oferece é a circulação de conhecimento e a construção de novas redes, é fundamental refletir que o/a cientista tem o 'direito' de falar em nome deste conhecimento.

A chave de leitura que propomos para essas questões são os contributos dos estudos póscoloniais e descoloniais (Mignolo, 2002; Quijano, 2005; Santos, 2000). A colonialidade do saber é um dos dispositivos de dominação e subalternização que deslegitima e marginaliza uns saberes em relação aos outros. Considerando que todo saber parte de algum lugar e que é dotado de pressupostos e orientações políticas, há, portanto, um local de enunciação determinado e um sujeito socialmente legitimado na prática da produção científica (Benzaquen, 2014) que abrange tanto o lugar de produção como o sexo de quem o produz. Em geral, como resultado da colonialidade do poder e do saber, o local de enunciação das ciências são os Centros do Norte e, como dito anteriormente, o seu sujeito é o homem branco, de classe média, cristão, heterossexual (Grosfoguel, 2008).

Como consequência da colonialidade do poder e do saber, há um mapa epistémico naturalmente hierarquizado no qual alguns países são, por defeito, os produtores de saber e de conhecimento (países do Norte) e outros ocupam o papel de objeto de estudo e de recetores das teorias produzidas em outras partes (países do Sul) (Almeida, 2011). Ou mais ainda, encontramos situações em que o Norte global apropria-se dos discursos críticos do Sul global e dissemina-os como se fossem seus. A partir destas considerações, a questão que se coloca é saber como as desigualdades geopolíticas manifestam-se nas dinâmicas (desiguais) da mobilidade científica.

\section{Cientistas latino-americanas em Portugal}

Ao longo da nossa investigação deparamo-nos com outras mulheres latino-americanas, que, como nós, estavam em Portugal na qualidade de cientistas. Como era de se esperar, em virtude do histórico de migração entre os dois países (Góis et al., 2009; Malheiros, 2007), as cientistas brasileiras são as mais acessíveis numericamente. Contudo, também encontramos argentinas, peruanas, uruguaias, chilenas e equatorianas. Vêm das mais diversas áreas de especialização - química, física, antropologia, ciências sociais, direito, cinema, biologia, engenharias - e estão inseridas em instituições espalhadas por todo o país - Lisboa, Oeiras, Coimbra, Faro, Porto, Évora, Braga. As posições que ocupam são, da mesma forma, bastante diversificadas - doutorandas, doutoradas, pós-doutorandas, investigadoras e professoras, embora, estas últimas em número inexpressivo.

Assim, desde o início, essas mulheres afastam-se do estereótipo das 'imigrantes de Terceiro Mundo', pobres, ignorantes e com baixos níveis de qualificação. De fato, os elevados níveis de qualificação associados a uma inserção laboral altamente especializada resultam não apenas numa diferenciação de classe, mas também na autoperceção. Salvo nós, autoras deste trabalho, nenhuma das cientistas com quem conversamos identificouse como 'imigrante', apesar de nenhuma delas ser de origem portuguesa. Palavras como 'estrangeira', 'expatriada', 'cientista internacional', 'cidadã do mundo' foram utilizadas para se definirem.

Marie $^{1}$, uma uruguaia pós-doutoranda, justifica sua incapacidade de identificar-se como uma imigrante:

Não posso reconhecer-me como tal, seria injusto, não me acho no direito de dizer que sou imigrante, porque minha experiência cá não é atravessada pelos problemas 
e dificuldades que os imigrantes em geral enfrentam. É muito mais difícil para eles do que para mim.

31 Ainda que compreendamos o posicionamento de Marie em não querer menosprezar as dificuldades das trajetórias migratórias mais comuns, ela acaba por reproduzir o imaginário de que a migração é sempre penosa, problemática e permeada por obstáculos, e que, portanto, seu deslocamento não pode ser enquadrado como uma migração. E ao mesmo tempo, minimiza o peso das adversidades que ela própria enfrenta.

Os motivos que trouxeram essas cientistas para Portugal são bastante diversificados, abrangendo questões familiares, convite da instituição, oferta de bolsa de investigação, procura de uma melhor formação, concursos. Nada que se afaste muito dos motivos que trouxeram as autoras deste trabalho para o país, ou outros grupos de mulheres imigrantes. A literatura sobre imigração brasileira (França, 2012; Góis et al., 2009; Malheiros, 2007; Padilla, 2007) e latino-americana (Padilla e Ortiz, 2009; Padilla, 2014) em Portugal tem mostrado que motivos familiares, ofertas de trabalho e a busca por melhores oportunidades de emprego são alguns dos principais motivos para o início de um projeto migratório.

$33 \mathrm{Na}$ verdade, o relato da experiência dessas mulheres na comunidade científica portuguesa, por diversas vezes, coincide com as nossas próprias experiências, especialmente, no que diz respeito ao momento presente, quando todas nós somos diariamente castigadas pelas consequências perversas da crise económica. Redução nos financiamentos para projetos de investigação, cortes em salários e nos números de bolsas e ausência de concursos para contratação são uma realidade que atinge todo o meio científico em Portugal de forma transversal. Contudo, esta realidade não pode e nem deve ser usada como bode expiatório para justificar a falta de espaço, para além do temporário e precário, para os/as investigadores/as imigrantes, que acabam sendo recrutados/as mais para contribuírem para os índices de internacionalização das instituições do que propriamente por conta de alguma política de integração permanente.

Para além do aumento da 'resistência' a cientistas imigrantes, com crescentes limitações legais para quem seja oriundo/a de países terceiros, atualmente, as posições oferecidas a este grupo são as mais precárias. Por sua vez, os lugares não precários no sector da docência e da investigação são espaços reservados quase que exclusivamente aos/às nacionais com 'padrinhos', para quem os concursos são desenhados. Ao que parece, em Portugal, preza-se mais a 'imobilidade científica' do que a 'mobilidade'. Fazer toda a formação - licenciatura, mestrado, doutoramento - na mesma instituição garante o conhecimento das pessoas certas e é visto como uma forma de fidelidade que mais tarde deverá ser recompensada. Assim, é comum que cientistas e investigadoras não portuguesas muito bem qualificadas não sejam contratadas quando concorrem com alguém que está na instituição há mais tempo, em geral, português/a. Neste caso o mérito do currículo não é paritário para competir com o peso do capital social e das redes pessoais de conhecimento. Todavia, é preciso reconhecer que, nos últimos anos, por conta da crise económica nacional, esta prática de 'recompensa à fidelidade institucional' ou de 'apadrinhamento' vem sendo desestruturada, pois a falta de concursos para os quadros tem, cada vez mais, atingido cientistas nacionais.

Rita, brasileira, há mais de quinze anos que se encontra no mesmo departamento; realizou o seu doutoramento ali, durante anos foi investigadora e atualmente possui um contrato precário de 'Professora convidada'. Era preciso dar-lhe uma posição de professora, para que ela pudesse ser coordenadora do novo programa de doutorado 
europeu. Era preciso que a coordenadora do novo programa de doutorado europeu fosse Rita porque, entre todas as pessoas que trabalham no departamento, ela é quem possui melhor qualificação. Sua produtividade é a mais alta do departamento, em número de publicações internacionais em revistas com impacto em projetos internacionais financiados. Inclusive, no passado, ganhou o primeiro lugar no concurso para Professora Associada, mas, sem grandes explicações, não pôde assumir o concurso. Até hoje, continua a esperar que abra uma nova vaga.

Me sugeriram não fazer muita confusão, pois aí é que jamais conseguiria entrar mesmo. Disseram também que mais cedo ou mais tarde abririam "minha" vaga. Lamentavelmente, é o caso descrito acima que é a regra: concursos para promover alguém que já estava na carreira docente, ou para incorporar um 'protegé'.

Além disso, vários são os relatos de situações em que a experiência do sexismo foi vivenciada, por elas e por nós, em gritos, ameaças de não renovação de contrato, negação de cartas de recomendação, ausência de convites para participar em júris de doutoramentos, entraves para defesas de teses, bloqueios para participar em eventos internacionais, exclusão de atividades científicas ou sociais, tratamento diferencial em relação aos investigadores no que diz respeito ao pagamento de salários e bolsas - os investigadores, por serem ainda reconhecidos como 'bread winner', costumam ter prioridade em receber o ordenado, e nós, mulheres, temos de nos conformar a receber quando houver recursos disponíveis pois "não precisamos do dinheiro, já que podemos depender de nossos companheiros ou pais".

Igualmente, compartilhamos um sentimento de rejeição de nossos nomes para assumir cargos de representação, chefia ou direção que não se explicariam por outra razão a não ser pelo fato de não sermos portuguesas. "É que você não é portuguesa e não sabe ainda muito bem como as coisas funcionam" - declara ter ouvido algumas vezes Carmem, investigadora argentina, como justificativa para o facto de ser mais adequado outra pessoa - uma portuguesa, no caso - assumir o cargo em questão. Lina, brasileira, professora Associada, quando foi escolhida para assumir o cargo que atualmente desempenha lembra de lhe terem dito: "Já estás cá há tanto tempo, que já és portuguesa." Estes dois casos mostram que não é, objetivamente, a qualidade do trabalho desenvolvido que legitima e valida a carreira científica em Portugal, mas pelo contrário, a questão de ser ou não ser portuguesa.

Elisa, brasileira pós-doutoranda, relata que uma vez organizaram no seu centro um lançamento de livros produzidos pelos/as investigadores/as fora de Portugal, mas, para sua surpresa, o seu livro não constava na lista. Os demais livros eram de colegas da Inglaterra, Espanha, Itália entre outros países europeus.

41 Esta é uma situação em que se pode identificar, claramente, as sutilezas das assimetrias geopolíticas. Apesar do crescimento económico do Brasil e da visibilidade que a ciência brasileira vem ganhando internacionalmente, especialmente em Portugal, não se apaga uma relação de dominação colonial do dia pra noite. Para todos os efeitos, em Portugal, a ciência brasileira ainda não é reconhecida como igual. O Brasil é, primordialmente, um país de 'campo', para onde os/as químicos/as vão em busca de plantas exóticas para matéria-prima das indústrias farmacêuticas e os/as cientistas sociais investigam fenómenos como violência urbana ou outros rituais e saberes 'ancestrais'. As discussões, as análises e a produção de conhecimento válidas são realizadas nos centros europeus. Logo, não haveria porque dar um destaque especial a um livro produzido no Brasil. 

Reis et al., 2010; Góis e Marques, 2007, 2014), eles não incorporam a perspectiva de género, nem denunciam a colonialidade do saber. Daí que o contributo deste artigo seja duplo, metodológica e epistemologicamente: a leitura crítica sobre um tema muito pouco debatido e a mobilidade científica com uma perspectiva de género, adotando também metodologias feministas que valorizam a categoria da experiência, categoria esta que reclamamos como central tanto para a investigação sobre as questões de género como com as relacionados com a imigração. Acreditamos que dar oportunidade a um conhecimento situado permite uma democratização do conhecimento, ao abrir o leque de possíveis interpretações, e por permitir discutir mais abertamente temas menos debatidos, por serem considerados menores ou espinhosos.

Sustentadas nos marcos epistemológicos e metodológicos das teorias feministas, partimos da nossa autobiografia e do nosso lugar de investigadoras imigrantes para refletir e analisar a experiência de cientistas latino-americanas em Portugal. O objetivo consistia em dar visibilidade a situações de exclusão, segregação e opressão que permanecem silenciadas, como consequência dos dispositivos de dominação patriarcal, colonialista, 
sexista e racista que operam no meio científico português, bem como das assimetrias geopolíticas internacionais.

Se, à primeira vista, a carreira das autoras deste trabalho, assim como a das investigadoras que entrevistamos, parece ser bem-sucedida, a verdade é que não se pode dizer que este foi um percurso fácil, sem adversidades e já consolidado. 0 conservadorismo, as hierarquias, os sexismos, o paternalismo e o ranço colonial do meio científico português marcam negativamente a experiência destas mulheres (e as nossas), tanto no que concerne à produção como à legitimação do conhecimento. Ou seja, ainda que mulheres cientistas possam ser consideradas possuidoras de um alto nível de capital social e cultural (Bourdieu, 2000) e façam parte da chamada 'elite intelectual', isso não evita que dinâmicas de exclusão, subalternização e segregação sexual e racial atuem.

Ser uma investigadora imigrante em Portugal é possível, mas não é fácil. 0 espírito livre de investigadora é cerceado por uma série de dispositivos de opressão que reforçam as desigualdades de género, de raça, de etnia e de nacionalidade.

Com isso não queremos dizer que as cientistas portuguesas também não estejam expostas a tais dispositivos, pois, como afirma Pereira (2014): "Há mais sexismo nas universidades do que em outras áreas em Portugal." Almejamos, pois, ressaltar a complexidade da experiência de ser cientista, mulher e imigrante no meio científico português. Mais ainda, não queremos rotular a carreira científica em Portugal como sendo impraticável; trata-se mais de um compromisso feminista de refletir sobre nossa realidade, aspirando com isto contribuir para a transformação social.

\section{BIBLIOGRAFIA}

ACKERS, Louise (2005), "Promoting scientific mobility and balanced growth in the European research area”. Innovation: The European Journal of Social Science: 301-317.

ACKERS, Louise (2010), “Internationalisation and equality. The contribution of short stay mobility

to progression in science careers". Recherches sociologiques et anthropologiges 1: 83-103.

ALMEIDA, Júlia (2011), “Geopolíticas e descolonização do conhecimento”. In Anais Seminário Nacional da Pós-Graduação em Ciências Sociais - UFES. Vitória.

ANZALDUA, Gloria (2012), Borderlands / La Frontera: The New Mestiza. Fourth Edition. Aunt Lute Books.

BANDEIRA, Lourdes (2008), “A contribuição da crítica feminista à ciência”. Revista Estudos Feministas 16(1): 207-28.

BAUDER, Harald (2012), “The international mobility of academics: A labour market perspective”. International Migration.

BENZAQUEN, Júlia Figueredo (2014), “O engajamento intelectual através do reconhecimento da geopolítica do saber”. Revista de Estudos AntiUtilitaristas e PosColoniais 3(2). 
BOURDIEU, Pierre (2000), o Poder Simbólico. Rio de Janeiro: Bertrand Brasil.

BRAH, Avtar (2006), "Diferença, diversidade, diferenciação”. Cadernos Pagu 26 (janeiro-julho): 329-376.

CUNHA, Teresa (2011), "Para além e de um Índico de desesperos e revoltas: Uma análise feminista pós-colonial das estratégias de Autoridade e poder das mulheres de Moçambique e Timor-Leste". Coimbra: Universidade de Coimbra - Centro de Estudos Sociais.

FRANÇA, Thais (2012), "Lindas mulatas com rendas de Portugal: A inserção das mulheres brasileiras no mercado de trabalho português". Tese de Doutoramento, Coimbra: Universidade de Coimbra - Centro de Estudos Sociais.

FURLIN, Neiva (2012), “A categoria de experiência na teoria feminista”, Revista Estudos Feministas 20(3): 955-972.

GÓIS, Pedro; MARQUES, José Carlos; PADILLA, Beatriz e PEIXOTO, João (2009), "Segunda ou Terceira Vaga? As características da imigração brasileira recente em Portugal”. Revista Migrações - Número Temático Migrações entre Portugal e América Latina n. 5 (ACIDI): 111-113.

GÓIS, Pedro e MARQUES, José Carlos (2007), Estudo Prospectivo sobre Imigrantes Qualificados em Portugal. Lisboa: ACIDI.

GÓIS, Pedro e MARQUES, José Carlos (2014), Processos de Admissão e de Integraç ão de Imigrantes Altamente Qualificados em Portugal e a sua Relação com a Migração Circular. Lisboa: ACIDI.

GROSFOGUEL, Ramón (2008), "Para descolonizar os estudos de economia política e os estudos pós-coloniais: Transmodernidade, pensamento de fronteira e colonialidade global". Revista Crítica de Ciências Sociais (80): 115-147.

HARAWAY, Donna (1988), "Situated knowledges: The science question in feminism and the privilege of partial perspective". Feminist Studies 14(3): 575-559.

HARDING, Sandra (1986), Perspectives on Gender and Science. Londres: Taylor \& Francis, Inc. HARDING, Sandra (1987), “Introduction: Is there a feminist method?". In Feminism and Methodology, edited by Sandra Harding. Bloomington: Indiana University Press, 1-14. HOOKS, Bell (2000), Feminist Theory: From margin to center. Londres: Pluto Press.

KING, Russell (2002), “Towards a new map of European migration”. International Journal of Population Geography 8(2): 89-106.

LORDE, Audre (1984), Sister Outsider: Essays and speeches. Berkeley: Crossing Press.

MALHEIROS, Jorge (2007), A Imigração Brasileira em Portugal. Lisboa: ACIDI.

MIGNOLO, Walter D. (2002), “The geopolitics of knowledge and the colonial difference”. South Atlantic Quarterly 101(1): 57-96.

MOHANTY, Chandra Talpade (1986), “Under Western eyes: Feminist scholarship and colonial discourses”. Boundary 2, 12(3): 333-358.

NARVAZ, Martha Giudice, e KOLLER, Silvia Helena (2006), "Metodologias feministas e estudos de gênero: Articulando pesquisa, clínica e política." Psicologia em Estudo 11, 3: 647-654.

NEVES, Sofi a, e NOGUEIRA, Conceição (2005), "Metodologias feministas: A refl exividade ao serviço da investigação nas ciências sociais”. Psicologia: Reflexão e Crítica 18 (3): 408-412.

PADILLA, Beatriz (2007), “A imigrante brasileira em Portugal: Considerando género na análise”. In A Imigração Brasileira em Portugal, edited by Jorge Malheiros. Lisboa: Jorge Malheiros: 113-135. 
PADILLA, Beatriz (2014), “Género y migraciones: Nuevas reconfi guraciones y protagonismos de las mujeres latinoamericanas. A modo de introducción”. Anuario Americanista Europeo 0 (11).

PADILLA, Beatriz, e ORTIZ, Alejandra (2009), “As migrações latino-americanas para Europa: Uma análise retrospectiva para entender a mobilidade actual”. Migrações 5: 19-35.

PEREIRA, Maria do Mar (2014), "Há mais sexismo nas universidades do que em outras áreas em Portugal.” Público, abril 2014.

PRADO, Renata Muniz, e FLEITH, Denise de Souza (2012), "Pesquisadoras brasileiras: Conciliando talento, ciência e família.” Arquivos Brasileiros de Psicologia 64 (2): 19-34.

QUIJANO, Anibal (2005), “Colonialidade do poder, eurocentrismo e América Latina” In A

Colonialidade do Saber: Eurocentrismo e ciências sociais. Perspectivas latino-americanas, Coleccion Sur Sur, CLACSO, edited by Ednargo Lander. Buenos Aires: Clacso, 107-130.

REIS, José; SANTOS PEREIRA, Tiago; TOLDA, João, e SERRA, Nuno (2010), Imigrantes em Portugal Economia, pessoas, qualificações e territórios. Coimbra: Almedina.

SANTOS, Boaventura de Sousa (2000), A Crítica da Razão Indolente: Contra o desperdício da experiência. 2. edição. Porto: Afrontamento.

SCHMIDT, Simone Pereira (2004), "Como e por que somos feministas". Revista Estudos Feministas 12 (SPE): 17-22.

SIMPSON, Jenniffer (2012), "Resistências epistemológicas feministas: Subjetivações emergentes como estéticas do existir". e-cadernos ces (18).

VELHO, Léa e LÉON, Elana (1998), “A construção social da produção científi ca por mulheres.” Cadernos Pagu 10: 309-344.

\section{NOTAS}

1. Os nomes das entrevistadas são fictícios.

\section{RESUMOS}

Apesar do crescente número de estudos que reconhecem a mulher como sujeito da migração, não se pode dizer que a maioria seja feminista. Nem que a diversidade da experiência migratória seja contemplada. Em geral, a migração feminina qualificada continua invisibilizada. Este artigo assume uma postura feminista e tem como objetivo refletir sobre os contributos que as epistemologias feministas oferecem aos estudos acerca da mobilidade de mulheres cientistas, especialmente em relação às denúncias das práticas hegemônicas de dominação. A partir de entrevistas qualitativas com cientistas estrangeiras em Portugal, discutimos questões como sexismo e racismo na academia. Enquanto autoras do artigo, identificamo-nos como imigrantes latino-americanas, académicas feministas radicadas em Portugal, demarcando o lugar de onde falamos e o contexto no qual esse trabalho é construído. 
Despite the growth of studies that recognize that women migrate, it is not possible to say that most of them are feminist, or that they address the diversity of the migration experience. In general, the migration of qualified female workers continues invisibly. This article takes a feminist standpoint and examines the contributions of feminist epistemologies to studies on the mobility of women scientists. Based on qualitative interviews with foreign scientists in Portugal, we discuss issues such as sexism and racism in Portuguese academia. As the article's authors, we identify ourselves as Latin American immigrants and feminist academics based in Portugal and define the place from which we speak and the context in which this work has been constructed.

Malgré l'augmentation du nombre d'études qui reconnaissent la femme en tant que sujet de la migration, nous ne pouvons pas affirmer que ces études soient majoritairement féministes et que la diversité de l'expérience de la migration y soit contemplée. En général, la migration féminine qualifiée demeure invisible. Cet article adopte une position féministe et vise à réfléchir sur les contributions que les épistémologies féministes ont pour les études sur la mobilité des femmes scientifiques, en particulier en ce qui concerne les allégations de pratiques hégémoniques de domination. À partir d'entretiens qualitatifs avec des scientifiques étrangères au Portugal, nous avons discuté de questions telles que le sexisme et le racisme dans le milieu universitaire. En tant qu'auteures de cet article, nous nous identifions comme des immigrantes latinoaméricaines, chercheures (universitaires) féministes établies, marquant ainsi l'endroit d'où l'on parle et le contexte dans lequel ce travail est construit.

\section{ÍNDICE}

Mots-clés: féminismes, épistémologies féministes, mobilité scientifique, études postcoloniales

Keywords: Feminism, Feminist epistemology, Scientific mobility, Postcolonial studies

Palavras-chave: feminismos, epistemologias feministas, mobilidade científica, estudos póscoloniais

\section{AUTORES}

\section{THAIS FRANÇA}

Investigadora de Pós-Doutoramento, Centro de Investigação em Ciências Sociais da Universidade do Minho

thaisfrancas@gmail.com

\section{BEATRIZ PADILLA}

Professora Associada, Instituto de Ciências Sociais e Centro de Investigação em Ciências Sociais da Universidade do Minho

padilla.beatriz@gmail.com 